\title{
Uma questão de poder: consumo sustentável e suficiência ecológica como discursos alternativos em prol da sustentabilidade
}

\author{
A question of power: sustainable consumption and ecological \\ sufficiency as alternative discourses for sustainability
}

\section{Marco Paulo Vianna Franco ${ }^{1}$}

\begin{abstract}
Resumo
Com base nos conceitos de consumo sustentável e suficiência ecológica, busca-se neste artigo contrapor os diferentes discursos relacionados ao tema, como a modernização ecológica, a abordagem de Amartya Sen, o movimento sul-americano do buen vivir e a defesa da justiça ambiental, assim como revelar a influência das relações de poder sobre o processo de transição para formas justas e sustentáveis de organização social.

Palavras-chave: Consumo Sustentável, Suficiência Ecológica, Relações de Poder.
\end{abstract}

\begin{abstract}
Based on the concepts of sustainable consumption and ecological sufficiency, this article seeks to distinguish between the different discourses associated with the topic, such as ecological modernization, Amartya Sen's approach, the South American buen vivir movement and the defense of environmental justice, as well as to reveal the influence of power relations over the transition into fair and sustainable forms of social organization.
\end{abstract}

Keywords: Consumption, Ecological Sufficiency, Power Relations.

\section{Introdução}

A ciência da sustentabilidade refere-se, de acordo com Baumgärtner e Quaas (2010), ao uso racional de recursos escassos, em uma perspectiva de longo prazo com incerteza intrínseca, visando à satisfação intertemporal das necessidades humanas e justiça nas relações entre humanos e entre humanos e natureza. De acordo com Scerri (2012), trata-se de uma

\footnotetext{
${ }^{1}$ Escola de Governo Professor Paulo Neves de Carvalho, Fundação João Pinheiro, Belo Horizonte, MG, Brasil. marco.franco@fjp.mg.gov.br

Artigo recebido em: 27/01/2018. Aceito para publicação em: 14/12/2018.
} 
disciplina que inclui aspectos ético-morais, em que não apenas a eficiência, mas também a justiça (intrageracional e intergeracional) é levada em consideração, ou seja, um campo que envolve tanto uma análise das possibilidades quanto das finalidades dentro do contexto biofísico e social das relações entre o homem e seu ambiente.

Ao popularizar o termo "desenvolvimento sustentável", o relatório de 1987 da Comissão Mundial sobre o Meio Ambiente e Desenvolvimento (também conhecido como Relatório Brundtland) menciona de forma inequívoca a necessidade de se alcançar padrões sustentáveis de consumo, ao defender que "para que haja um desenvolvimento global sustentável é necessário que os mais ricos adotem estilos de vida compatíveis com os recursos ecológicos do planeta - quanto ao consumo de energia, por exemplo" (CMAD, 1991, p.10).

A mesma ideia foi apresentada no debate dos anos 70 entre Paul Ehrlich, John Holdren e Barry Commoner ao inserir os impactos da afluência - entendida como a riqueza per capita, acumulação material individual ou ainda intensidade de produção e consumo - na sua famosa equação em que os impactos ambientais seriam dados pelo produto entre indicadores populacionais, tecnológicos e de afluência. Enquanto o discurso acerca da questão populacional se tornou dominante, pouco se avançou na análise dos efeitos da afluência ou, mais especificamente, do consumo, pelo menos até o início dos anos 90, quando toma corpo o discurso da modernização ecológica (ROPKE, 2005).

Conceito concorrente ao de consumo sustentável, a suficiência ecológica é definida como a restrição voluntária do consumo individual motivada por uma responsabilidade ecológica inserida no quotidiano dos indivíduos relativa ao futuro das espécies humana e não humanas (HEINDL \& KANSCHIK, 2016). Tal formulação implica na redução do consumo em valores absolutos vis-à-vis os limites biofísicos ou capacidade de suporte do 
planeta em relação à pressão imposta pela escala das atividades humanas, material e energicamente.

$\mathrm{Na}$ tentativa de se compreender melhor o escopo, limites, significados e consequências da discussão suscitada pelos conceitos de consumo sustentável e suficiência ecológica, este trabalho traz à luz alguns dos discursos que se opõem ou complementam, principalmente no contexto das relações de poder embutidas em tópico tão complexo e polêmico. Na seção 2 deste artigo, parte-se para uma análise mais pormenorizada da ideia de consumo sustentável, tendo em vista suas diferentes interpretações e apropriações através de discursos técnicos e ideológicos. Na seção 3, apresenta-se a suficiência ecológica como forma de contribuir para uma visão de consumo sustentável forte, baseada no voluntarismo dos indivíduos. A abordagem de Amartya Sen é brevemente apresentada como teoria que corrobora o papel da suficiência voluntária com base nas liberdades individuais e na conexão entre a satisfação das necessidades humanas e a sustentabilidade ambiental. Em seguida, adentra-se o discurso praticado pelo movimento do buen vivir, intimamente relacionado aos princípios da suficiência ecológica e de origem sul-americana. A defesa da justiça ambiental também é elencada como forma de resistência ao discurso dominante da modernização ecológica com foco nos conflitos socioambientais e nas relações de poder entre Norte e Sul. A ecologia profunda alude ao valor intrínseco e direitos da natureza. Finalmente, o ecossocialismo é colocado como modelo alternativo de organização social que contribui para a discussão sobre suficiência ecológica ao conjugar o conceito marxista de emancipação humana com condicionantes ecológicos. A seção 4 traz alguns comentários finais.

\section{Os Discursos acerca do Consumo Sustentável}

O Ministério do Meio Ambiente define consumo sustentável como: 


\begin{abstract}
o uso de bens e serviços que atendam às necessidades básicas, proporcionando uma melhor qualidade de vida, enquanto minimizam o uso dos recursos naturais e materiais tóxicos, a geração de resíduos e a emissão de poluentes durante todo o ciclo de vida do produto ou serviço, de modo que não se coloquem em risco as necessidades das futuras gerações (BRASIL, 2011, p. 6).
\end{abstract}

Além desse conceito mais amplo, há também que se diferenciar entre o consumo sustentável fraco e forte. O primeiro está relacionado aos ganhos de eficiência nos processos de produção e consumo em termos dos fluxos presentes de matéria e energia, tanto em relação à utilização de recursos naturais quanto à geração de resíduos. $\mathrm{O}$ consumo sustentável forte, por sua vez, trata de mudanças significativas nos hábitos de consumo dos indivíduos mais ricos na direção da redução dos seus níveis absolutos de transformação de matéria e energia (SEDACKLO et al., 2014).

De acordo com Sedlacko et al. (2014), a disseminação do termo "consumo sustentável” não foi suficiente para impulsionar pesquisas e políticas públicas que realmente se dediquem a mudanças no estilo de vida dos mais ricos, ou seja, relacionadas ao consumo sustentável forte. Ao contrário, padrões de consumo sustentável são tomados em sua vertente "fraca", como parte do discurso de modernização ecológica, percebidos como sinérgicos em relação ao crescimento econômico continuado, fonte de novas oportunidades de negócios por meio da criação de demanda por produtos ecologicamente "competitivos" e sem qualquer referência à escala quantitativa do consumo ou às necessidades de consumo básico de populações mais pobres. A sinergia entre o discurso da modernização ecológica e o crescimento econômico continuado se baseia em grande parte na ideia da desmaterialização da economia, em que o avanço tecnológico tornaria possível um crescimento econômico sem necessidade de acréscimo nos fluxos de matéria e energia (SÁ BARRETO, 2014). Os autores destacam como exemplo um documento do Programa das Nações Unidas para o Meio Ambiente, que ratifica essa visão ao defender que o consumo sustentável não estaria relacionado a consumir menos, mas sim a consumir de uma 
forma diferente, com maior eficiência e qualidade de vida (UNEP/CDG, 2000). O crescimento econômico, entendido como condição para a estabilidade social de sociedades capitalistas, é caracterizado como solução para os problemas sociais e ambientais. Trata-se de uma visão cornucopiana, baseada em argumentos dúbios relativos à capacidade de desmaterialização da economia, que legitima uma apropriação desigual e ilimitada de recursos naturais.

Lorek e Fuchs (2013) contribuem para a análise dos discursos acerca do consumo sustentável, ao afirmar que estudos na área pouco se relacionam com outras linhas de pesquisa relativas ao desenvolvimento sustentável, como a teoria do decrescimento econômico, apesar dos ganhos potenciais de uma abordagem sistêmica dos desafios colocados à ciência da sustentabilidade. Segundo as autoras, tal fato se deve à dominância do discurso da modernização ecológica no contexto do consumo sustentável, em que ganhos de eficiência decorrentes do progresso tecnológico são o foco principal. Ainda, afirma-se que modos de governança baseados no consumo sustentável fraco, resultado dessa dominância do discurso, não conseguem prover respostas satisfatórias a problemas como o limite biofísico da capacidade de suporte dos ecossistemas, ou como os conflitos distributivos inerentes à acumulação de riqueza característica de sistemas econômicos capitalistas. Por outro lado, o consumo sustentável forte seria um elemento essencial a uma ciência da sustentabilidade interessada na satisfação intertemporal das necessidades humanas e na justiça nas relações entre humanos e entre humanos e natureza, mas que ainda carece de força política.

Mesmo após os resultados de estudos empíricos que demonstram um desacoplamento entre riqueza e bem-estar (ou felicidade) à medida que se move em direção a maiores níveis de afluência individual, fenômeno conhecido como paradoxo de Easterlin (EASTERLIN, 1974; CLARK et al., 2008), o discurso do consumo sustentável forte ainda parece marginalizado, 
em grande parte devido à oposição de segmentos sociais dominantes, como consumidores e empresas (ROPKE, 2005). Novos resultados de pesquisas sobre os fatores envolvidos no bem-estar, se bem comunicados e entendidos, poderiam auxiliar o discurso científico e político em defesa do consumo sustentável forte. Mecanismos de retroalimentação entre pesquisa científica e discursos sociais (por exemplo, entre novos conhecimentos advindos das ciências ambientais e movimentos ambientalistas) poderiam levar à emergência de novas agendas políticas que, entretanto, precisam competir com outras agendas - mais ou menos antagonistas - elaboradas por outras interações entre discursos científicos e sociais. O desafio colocado aos discursos em favor de um consumo sustentável forte, portanto, seria se sobrepôr à dominância de uma agenda política calcada em ideias e práticas relacionadas à modernização ecológica.

Uma análise das relações de poder subjacentes à apropriação dos discursos relacionados ao consumo sustentável é frequentemente omitida nas pesquisas e políticas públicas sobre o tema (FUCHS et al., 2015). A ausência de uma abordagem explícita e abrangente acerca dessas relações pode frustrar a compreensão dos mecanismos que guiam o consumo, dificultando a concepção de propostas consistentes em favor de mudanças nos hábitos dos consumidores e que resultem em menor pressão sobre o meio ambiente e maior justiça social. Ainda segundo Fuchs et al. (2015, p. 306, tradução nossa):

O poder é intrínseco à interação humana, à organização social e à conformação da mudança social. O poder é essencial para o entendimento acerca das causas do sobreconsumo e cria barreiras contra tentativas de torná-lo sustentável e de identificar onde estão os pontos de intervenção potencialmente efetivos. Pesquisas e ações em consumo sustentável e reduções absolutas precisam levar em conta quem controla o processo, define as regras e as narrativas, seleciona os instrumentos de governança e seus objetivos, e assim influencia o comportamento e as opções das pessoas, assim como seus impactos. 
A dominância do discurso da modernização ecológica deve ser interpretada no contexto de um consenso hegemônico capitalista em sentido Gramsciano. Tal consenso se estabeleceu nas esferas política e científica desde o começo do século XIX e se intensificou no período pós-guerra, com a virtual universalização do modo capitalista de desenvolvimento social. A capacidade do mercado de regular a produção, distribuição e consumo de commodities necessárias à vida moderna se tornou a base de uma agenda global que se perpetua e multiplica, amparada por instituições controladoras de poder civil e militar.

Soma-se ao discutido acima a ideia da "ilusão da soberania do consumidor" (FELLNER; SPASH, 2014). Um dos cânones da economia neoclássica, a soberania das preferências dos consumidores via demanda por bens e serviços torna sedutora a ideia de que a degradação social e ambiental decorrente das práticas de mercado é, em última instância, o resultado agregado de ações individuais autônomas e, portanto, justificada. Assim, se os consumidores não compram produtos "verdes", se optam por uma dieta rica em carnes, se escolhem um estilo de vida intenso em emissões de gases de efeito estufa ou se não dão valor à biodiversidade, então os mercados deveriam, de acordo com essa corrente de pensamento, refletir esse comportamento, maximizando o bem-estar econômico dos indivíduos. Porém, como defendem os autores, consumidores não detêm de fato o controle da economia ou mesmo do seu papel nela. Suas escolhas e preferências são construções sociais e culturais, sujeitas a discursos dominantes colocados em prática por meio da imposição de quem controla o capital político, intelectual ou social. Atos legislativos, propaganda comercial, seleção de investimentos, direcionamento de inovações tecnológicas e dogmatismo científico são ferramentas poderosas no processo de mudança dos hábitos dos consumidores. A infraestrutura rodoviária, a oferta massiva de combustíveis fósseis, a legislação de transportes terrestres, o marketing da indústria automobilística ou as inovações 
técnicas do setor compõem, por exemplo, um contexto muito específico no qual indivíduos tomam suas decisões quotidianas acerca da compra de um automóvel de forma não muito soberana, em contraposição ao discurso neoliberal.

Portanto, a soberania do consumidor torna-se um mito ao se empregar a análise das relações de poder e como elas podem obscurecer a realidade e evitar rupturas na ordem estabelecida (LATOUCHE, 2007). Tal como na visão econômica schumpeteriana, os produtores iniciam mudanças nos hábitos de consumo ao "educar" os consumidores a desejar coisas novas. Destarte, a substituição de antigos hábitos de consumo por novos a partir da oferta que cria sua própria demanda vai ao encontro da ideia da "ilusão da soberania do consumidor". Em termos do consenso hegemônico capitalista, a ideologia da soberania do consumidor tem no individualismo sua justificativa moral. Somado à ordem social baseada no livre mercado e o ideal de liberdade individual, tem-se aceita a afirmação de preceitos por discursos dominantes sem a necessidade de haver correspondência direta com a realidade social.

A tentativa de introdução do discurso do consumo sustentável forte, baseado na ideia também sedutora de que a redução do consumo seria acompanhada pela redução na carga de trabalho com ganhos redobrados de bem-estar (a expressão "dividendos duplos" é comumente usada na literatura), pode, por sua vez, apresentar um contraponto em tais relações de poder, sendo ela mesma carregada de visões ideológicas moralistas (ALCOTT, 2008). Como colocado por Ropke (2005, p. 11, tradução nossa):

A promoção da ideia do dividendo duplo pode apresentar uma face moralista: deveríamos simplesmente parar com todo esse consumismo imoral e perverso e transformar nossos valores materialistas, pois isso nos beneficiaria - uma ideia que se alinha às antigas críticas à sociedade do consumo [...] Infelizmente, a questão não é tão simples assim. Mesmo sendo fácil imaginar uma sociedade com menos consumo e mais qualidade de vida devido à redução dos níveis de stress e melhores condições coletivas, menos "custos de defesa" etc., é difícil imaginar como alcançar esse 
resultado, uma vez que as pessoas na prática fazem outras escolhas. O ponto principal é que o consumo está inserido na vida social e cultural - não é algo que possa ser isolado e reduzido sem interferir nos fundamentos da vida quotidiana. O consumo não está apenas relacionado ao egoísmo, mas pode também estar ligado às motivações mais altruístas (MILLER, 1995; CAMPBELL, 1987; WILK, 2004). Assim, enfrentamos um verdadeiro dilema quando defendemos que a redução do consumo é algo extremamente necessário.

\section{O Novo Discurso da Suficiência Ecológica}

A suficiência ecológica (ou ecossuficiência) está necessariamente ligada à redução do consumo em níveis absolutos, e mesmo que não haja provas de sua efetividade enquanto instrumento de proteção ambiental, a incerteza associada aos impactos ecológicos do crescimento econômico justificaria sua aplicação ao menos de forma a se somar ao leque de ações e políticas em favor da sustentabilidade nas atividades humanas (HEINDL; KANSCHIK, 2016). Além da redução no consumo, a suficiência aponta para um aumento no consumo de bens e serviços não poluentes e fora do sistema de mercado, o que leva à caracterização de indivíduos mais autossuficientes quanto ao seu consumo pessoal.

Heindl e Kanschik (2016) enfatizam quatro pontos principais na definição de suficiência ecológica: (i) objetivo ecológico, (ii) abordagem individual, (iii) foco no consumo e (iv) iniciativa voluntária. A necessidade do último ponto é tema polêmico na literatura - ações coercitivas em prol da suficiência poderiam ser mais efetivas, mas esbarram na sua incompatibilidade com os valores das sociedades liberais modernas - e sua inclusão diz respeito principalmente a estratégias bottom-up de redução do consumo, sem a imposição de um planejamento central tal como é hoje característico do processo democrático. Não obstante a ausência de imposições específicas aos consumidores, fica implícito o imperativo de se indicar aos mesmos qual seria o objetivo ecológico em vista, um limite quantitativo fundamentalmente não arbitrário, dado pela realidade objetiva 
das condições biofísicas do ambiente, no qual indivíduos possam basear suas decisões voluntariamente. Entretanto, se as necessidades humanas básicas, culturalmente estabelecidas, por si só já superarem os limites biofísicos do planeta, tem-se um dilema moral ainda pouco estudado na literatura.

O papel dos discursos e das relações de poder é central para a preservação das liberdades individuais e da noção de suficiência ecológica voluntária (HEINDL; KANSCHIK, 2016). Os motivos pelos quais indivíduos adotam a prática da suficiência, como a formação de identidade pessoal (ELLIOTT, 2004; MANSVELT, 2005), novas percepções em relação ao conceito de qualidade de vida (simplificação da vida, maior proximidade com a natureza e a comunidade, libertação da opressão do sobreconsumo etc.) (FISCHER; GRIESSHAMMER, 2013) e outros benefícios não materiais, estão em geral sujeitos a fortes influências de discursos dominantes. Em todo caso, são escassos os estudos sobre os impactos de políticas públicas favoráveis à noção de suficiência, tanto na esfera individual quanto sob a forma de programas políticos abrangentes, e ainda mais raros aqueles com o objetivo de mensurar as barreiras colocadas pelo discurso dominante da modernização ecológica à disseminação e operacionalização dos preceitos da ecossuficiência. Por outro lado, são abundantes os estudos que relacionam poder e consumo em perspectivas mais amplas, frequentemente associadas à economia política de Karl Marx ou ao pós-estruturalismo (MANSVELT, 2005).

Por fim, o conceito de suficiência ecológica se distancia da visão antropocêntrica, na qual a natureza constitui apenas fonte de recursos e serviços para a satisfação das necessidades humanas, sem nenhum valor intrínseco. Nessa visão, a preservação da natureza só faria sentido na medida em que seus impactos positivos sobre a humanidade superem os negativos. Há uma hierarquia entre as espécies, com o homem no topo da pirâmide. Ao pregar a responsabilidade ecológica e a preocupação com gerações futuras humanas e não humanas, a ecossuficiência aproxima-se da 
abordagem denominada "biocêntrica", em que a natureza é o cerne da discussão e da qual o homem é parte indissociável.

\section{A Abordagem de Sen}

Amartya Sen $(1992,1999)$ propõe uma interessante abordagem na qual há a ideia de que os limites da preservação ambiental estariam ligados à manutenção do conjunto de necessidades mais básicas dos indivíduos, que seria culturalmente estabelecido. Porém, se, por um lado, a satisfação de tais necessidades básicas (por meio da autossuficiência ou mesmo via políticas públicas, avanços técnicos ou novos arranjos sociais) pode levar à conservação ambiental, por outro lado não há garantias quanto à perpetuação da base de recursos naturais mesmo quando a demanda é constituída apenas por necessidades básicas - bastaria pensar em um crescimento populacional acima da capacidade de suporte dos ecossistemas do planeta.

Ademais, assim como o acesso à base de recursos naturais deve respeitar princípios de suficiência e equidade intergeracional, o próprio conjunto das necessidades mais básicas da geração presente não deveria ser sacrificado em prol das gerações futuras, as quais, por sua vez, enfrentariam restrições semelhantes e assim sucessivamente, com a perda de bem-estar na geração presente e nas futuras. A abordagem de Sen constitui, portanto, uma análise normativa do equilíbrio entre bem-estar social e sustentabilidade ambiental (BALLET et al. 2013), com base em julgamentos de valor e na liberdade individual usufruída por indivíduos preocupados não somente com seus próprios interesses, mas com o bem-estar alheio, inclusive de forma intergeracional e das espécies não humanas, sujeitos ao contexto social, indo além da visão dominante de homo economicus consolidada pela teoria utilitarista neoclássica. 
A abordagem de Sen é capaz de levar em conta as restrições às quais as escolhas estão submetidas, assim como a ausência de alternativas no exercício das liberdades individuais. Assim é possível compreender melhor a relação entre o homem e o meio ambiente dentro de um contexto de evolução técnico-social e, partir daí, elaborar políticas públicas visando concomitantemente o bem-estar humano e a sustentabilidade ambiental. A busca por novas formas de organização social que levem a escolhas com menores impactos ambientais constitui, aliada à justiça intergeracional, um campo fértil para o desenvolvimento da ciência da sustentabilidade.

Para a efetivação desse discurso, é fundamental que se conheça o grau de vulnerabilidade, a habilidade de adaptação e resistência que um indivíduo apresenta face às exigências de mudanças no uso de recursos naturais. Da mesma forma, é preciso compreender como as suas ações retroagem sobre o meio ambiente. Citando exemplo de Ballet et al. (2011), a discussão intergeracional acerca do desflorestamento deve levar em consideração a ausência de alternativas das comunidades locais à utilização da madeira e do carvão vegetal como fontes de energia para sua subsistência. Por outro lado, caso o desflorestamento seja motivado pela formação de pastagens extensas ou monoculturas de biocombustíveis atividades não diretamente relacionadas a necessidades básicas -, a discussão intergeracional ganha outro enfoque, de acordo com as oportunidades e restrições subjacentes e com seus resultados em termos de bem-estar básico hoje e no futuro.

\section{O Movimento do "Buen Vivir"}

Outro discurso moderno associado aos conceitos de consumo sustentável e suficiência ecológica se inspira em tradições antigas de povos sul-americanos, de origem andina e amazônica, por meio do movimento social e filosofia política do buen vivir (termo adaptado da expressão 
quéchua Sumak Kawsay, que significa "vida digna, com plenitude"). Caracteriza-se como um movimento que prega outros conceitos e valores para termos como desenvolvimento e bem-estar, baseados em uma forte vivência comunitária e em harmonia com o ambiente (ACOSTA, 2015). O valor intrínseco da natureza é tornado explícito, sendo ela uma portadora de direitos. A degradação ambiental causada pela criação de necessidades artificiais, por exemplo, viola os direitos da Pachamama (o conceito de Pachamama é complexo e assemelha-se às definições de Gaia, "mãe Terra" ou "mãe natureza") segundo os critérios do buen vivir (ZAFFARONI, 2011). A atividade econômica é centrada na solidariedade, na autonomia local, no uso regenerativo dos recursos e resíduos e no direito de todos os povos a uma vida digna, avaliada de forma autorreferenciada.

O buen vivir é um exemplo de discurso em favor do consumo sustentável e da suficiência ecológica. Propõe alcançar seus objetivos ao atribuir um papel central à comunidade enquanto agente regulador da vida social, reduzindo o alcance do mercado e do Estado. Entretanto, Acosta (2015) reconhece a necessidade de se enfrentar relações de poder fortemente desfavoráveis ao movimento do buen vivir, desafio que vai além do discurso no processo de implantação dessa nova realidade. Ainda assim, já se notam alguns passos nessa direção, como a incorporação da filosofia do buen vivir como princípio constitucional do Ecuador. Com uma economia baseada em commodities para exportação, o país ainda luta contra o poder político de grupos influentes ligados a projetos extrativos de larga escala, que tipicamente envolvem perdas sociais e ambientais (VILLALBA-EGUILUZ; ETXANO, 2017).

\section{A Defesa da Justiça Ambiental}

A justiça ambiental compõe parte fundamental das discussões que formam o campo da ecologia política. Segundo Martinez-Alier (2002), tal 
disciplina poderia ser definida como "o estudo dos conflitos distributivos ecológicos", em que se insere a análise das conexões entre inequidade de poder e degradação ambiental num contexto de crescimento econômico. A questão do consumo sustentável e da suficiência ecológica guarda relação estreita com a justiça ambiental. Uma primeira ideia parte do pressuposto de que, dados os limites ecológicos do planeta, para que os pobres possam satisfazer suas necessidades mais básicas, os ricos teriam que reduzir seu próprio consumo, liberando recursos escassos exigidos em áreas mais vulneráveis do globo (SACHS, 1993). Conforme Heindl e Kanschik (2016), há um conflito entre os princípios da suficiência ecológica e da justiça social: a primeira propõe um limite superior e a segunda um limite inferior para o consumo social. É preciso observar o intervalo possível de ação conjunta, uma vez que sem levar em conta as demandas por justiça social não haveria apoio público para ações relativas à suficiência; sem a observância da suficiência ecológica, alternativamente, haveria a ruptura dos já mencionados limites ecológicos e a conseguinte degradação social e ambiental em larga escala.

Sawyer (2002) discute se a redistribuição de renda e a eliminação da pobreza levariam a uma menor ou maior degradação ambiental. A resposta dependeria principalmente da dinâmica populacional e de mudanças nos hábitos de consumo, estes entendidos de forma sistêmica, com impactos ambientais diretos e indiretos (decorrentes dos processos produtivos, transporte, comercialização etc.), integrados no ciclo econômico de produção de bens e serviços e determinados pelas relações internacionais entre Norte e Sul (na medida em que as exportações de commodities dos países do Sul para os países do Norte caracterizam-se pela transferência de recursos naturais sob termos de troca deteriorados). O reconhecimento da complexidade do tema evita a visão simplista na qual a degradação ambiental é causada pelo consumo nos países do Norte e pela pobreza nos países do Sul, alvo fácil de discursos e poderes em linha com a modernização 
ecológica e o crescimento econômico a todo custo, que se utilizam de demandas sociais para justificar a expansão econômica e de restrições ambientais para fomentar novas oportunidades de negócios "verdes".

\section{A Ecologia Profunda}

Em relação à preocupação com gerações presentes e futuras de populações não humanas, ou seja, com a própria natureza (sem adentrar na discussão filosófica acerca da dicotomia entre o humano e o natural), a suficiência ecológica se aproxima do biocentrismo, no qual há um reconhecimento aberto da natureza como entidade possuidora de valor intrínseco e portadora de direitos. A história do pensamento ambientalista é fonte rica em exemplos de discursos que, ao adotarem princípios e proposições biocêntricos, alinham-se à suficiência ecológica de um ponto de vista ético.

Um apanhado mais recente dessa história apontaria para pensadores como Henry David Thoreau (1817-1862), autor transcendentalista americano que acreditava que o consumo conspícuo não era apenas dispensável, mas um obstáculo à elevação moral da humanidade; John Muir (1838-1914), preservacionista americano visto como o "pai dos parques nacionais" e defensor da vida selvagem, intocada pelo homem; e Aldo Leopold (1887-1948), silviculturista, ecólogo e conservacionista, propositor de uma "Ética da Terra" baseada na integridade e estabilidade de comunidades bióticas. Autor de uma das mais influentes obras do pensamento ambientalista, A Sand County Almanac (1949), Leopold associou o direito de propriedade a valores éticos relacionados aos conceitos de responsabilidade e cuidado como base para as relações entre homem e natureza. Haveria um princípio de reciprocidade de direitos e deveres que reflete a interdependência entre o bios e o anthropos. Tal reciprocidade se daria a partir da consciência ecológica dos proprietários - aqui, 
consumidores - acerca do valor de manifestações bióticas não humanas (FERREIRO, 2009).

Não obstante a prominência desses autores, a ecologia profunda de Arne Næss (1912-2009) poderia ser considerada como a quintessência do biocentrismo. Ao mesmo tempo filosofia e movimento ambientalista, a ecologia profunda propõe o reconhecimento do valor intrínseco de todas as formas de vida como base para a elaboração de políticas ambientais. O adjetivo "profunda" se refere ao nível de questionamento acerca dos valores e propósitos da existência humana em sua relação com seu ambiente e outros seres vivos. Trata-se de um profundo escrutínio de causas e motivações fundamentais em cada tomada de ação com implicações sobre a vida em geral. Abordagens mais rasas se contentariam com soluções de curto-prazo, em geral modernizantes no sentido tecnológico e conservadoras quanto ao modo de organização social prevalecente (i.e., partidárias do discurso de modernização ecológica). Uma abordagem profunda deve, necessariamente, questionar o sistema social dominante e redesenhá-lo de acordo com valores que preservem a vida em sentido lato, com toda sua diversidade biológica e cultural.

Embora a ecologia profunda tenha sido taxada de anti-humana e atacada por isolar o homem como entidade externa ao conceito integral de natureza, a maior contribuição da filosofia de Næss está relacionada à equiparação entre os valores intrínsecos de homem e natureza, entendidos como detentores de direitos fundamentais, como à vida e ao desenvolvimento (NÆSS, 1989). Assim, a ecologia profunda se apresenta como discurso caro à suficiência ecológica, reunindo elementos presentes no transcendentalismo de Thoreau, no preservacionismo de Muir, na Ética da Terra de Leopold, no buen vivir (a natureza como entidade detentora de direitos) e na abordagem de Sen (a preocupação com espécies não humanas). 


\section{Ecossocialismo}

A economia política de Marx, segundo a maioria dos ambientalistas, não trata de questões ecológicas, mantendo caráter produtivista e defendendo que a natureza seria, em última instância, uma das forças pelas quais o proletariado tomaria seu destino em suas próprias mãos. Entretanto, análises recentes (BURKETT, 2009; FOSTER, 2000; LÖWY, 2001; 2015) apresentam a visão na qual Marx teria apontado para o perigo de uma "ruptura metabólica" entre sociedade e natureza (apesar da permanência de uma visão essencialmente antropocêntrica). Os fluxos de matéria e energia requeridos pela expansão do sistema capitalista não poderiam ser permanentemente atendidos pela capacidade de carga do planeta. A partir desse ponto de vista, desenvolveu-se o arcabouço teórico do ecossocialismo (ou eco-marxismo).

No seu "Manifesto Ecossocialista" (2001), Joe Kovel e Michael Löwy apontam como o capital reduz a humanidade à posição de mero reservatório de força de trabalho, o que é intensificado pela promoção do consumismo e da despolitização da população. O novo modelo ecossocialista, por outro lado, reteria os objetivos emancipatórios associados ao conceito original de socialismo, rejeitando, porém, propostas reformistas mais atenuadas colocadas em prática nas social-democracias capitalistas, assim como estruturas produtivistas tão caras às vertentes mais burocratizantes do socialismo. Colocam-se em primeiro lugar o caráter social da produção e seus condicionantes ecológicos, em detrimento do imperativo do crescimento econômico a todo custo. Não se trata de um paradigma da escassez, mas de uma transformação de valores, focada na satisfação de necessidades humanas e na qual aspectos qualitativos se sobrepõem aos quantitativos. No jargão marxista, essa transição diz respeito também à primazia do valor de uso sobre o valor de troca. De acordo com Kovel (2002), a ênfase sobre o valor de troca nas economias de mercado, com a constante necessidade de 
compra-e-venda para a própria sobrevivência do indivíduo, leva à produção de bens até então sem valor de uso, simplesmente devido ao seu poder de sustentar a capacidade de comprar outros bens.

Para Löwy (2001), enquanto corrente intelectual, o ecossocialismo seria a combinação do socialismo com a ecologia política. Nesse sentido, ele se aproxima da defesa da justiça ambiental, atuando em favor dos interesses dos trabalhadores, de comunidades tradicionais e do Sul global como um todo, opondo-se às soluções modernizantes de cunho capitalista no contexto da sustentabilidade. A causa-raiz da insustentabilidade do atual modelo econômico está fundamentada no princípio de acumulação de capital, que perpassa a organização e a lógica dos processos de produção, distribuição e consumo. Do ponto de vista sócio-ecológico, é impossível estender-se a todos, em nível planetário, o consumo ostensivo e o desperdício de recursos típico dos países mais ricos do Norte sem que haja uma ruptura metabólica irreversível com consequências desastrosas. Uma economia ecossocialista deve, portanto, se inserir nas circunstâncias sociais e ambientais que lhe são apresentadas, promovendo mudanças éticas, comportamentais e organizacionais profundas. $\mathrm{O}$ abandono de hábitos artificiais de consumo e a adoção de princípios relacionados à suficiência ecológica são pontos-chave dessa transição.

\section{Considerações Finais}

Foram apresentados acima os conceitos de consumo sustentável, em suas variantes forte e fraca, e de suficiência ecológica. $\mathrm{O}$ discurso dominante da modernização ecológica, baseado no consenso hegemônico capitalista, no qual problemas sociais e ambientais são tratados por meio da extensão do alcance dos mercados e do papel salvador do progresso tecnológico, foi associado ao consumo sustentável fraco, baseado em ganhos de eficiência, inovação tecnológica e geração de novas oportunidades de negócios "verdes". Em contraste, discursos como a abordagem de Sen, o movimento buen vivir, a defesa da justiça ambiental, a ecologia profunda e o ecossocialismo se aproximam das ideias promovidas pelos princípios do consumo sustentável forte e da suficiência ecológica, em que se integram as reduções absolutas 
das transformações de matéria e energia, a justiça social e novas percepções acerca de bem-estar, qualidade de vida, dignidade, comunidade e natureza.

O debate sobre a sociedade de consumo e suas consequências ecológicas é polêmico, complexo, plural e muitas vezes contraditório. Nele se inserem pontos de vista distintos mesmo dentro de um mesmo grupo de interesse, disciplina científica, povo ou cultura. Argumentos econômicos, ecológicos, morais e políticos se sobrepõem num contexto social em que os discursos e as relações de poder desempenham papel tão importante quanto o de verdades científicas amplamente aceitas. Tais verdades, por sua vez, se sujeitam à apropriação por discursos dominantes de grupos de interesse que, em que se pese seu poder e influência, são capazes de formar e consolidar determinadas visões de mundo e, consequentemente, a própria realidade social. Qualquer mudança nos padrões atuais de consumo - ou de acumulação, termo mais amplo que explicita a lógica unidirecional de um sistema econômico movido a crescimento ad infinitum - depende fundamentalmente de uma ruptura do discurso e do poder hegemônico do consenso capitalista que, se não levada a cabo de forma organizada e consentida, de outra forma será dada tragicamente pelos limites ecológicos do planeta. Como bem colocado por Fuchs et al. (2015, p. 9, tradução nossa):

Para aqueles de nós realmente preocupados com uma existência em longo prazo tal como a conhecemos hoje, evitar discutir o papel das relações de poder é corroborar com um sistema inerentemente insustentável e injusto, tanto no curto quanto no longo prazo, nas esferas doméstica e internacional. Se afastar da questão do poder permite a continuidade de tendências atuais junto com seus desdobramentos lógicos e trágicos. Interrogar sobre o poder, desvelar o que está sob a superfície e expor suas inequidades é uma obrigação civil, imperativo da sustentabilidade e pré-requisito para a justiça. Já é tempo para que cientistas sociais, cientistas naturais e humanistas, assim como aqueles em áreas aplicadas como administração e engenharia, estudem, questionem e, por conseguinte, desafiem o poder. O consumo não pode ser sustentável nem suas reduções absolutas se permanecermos aquém disso. 


\section{Referências}

ACOSTA, A. El Buen Vivir como alternativa al desarrollo: algunas reflexiones económicas y no tan económicas. Política y Sociedad, v. 52, n. 2, p. 299-330, 2015. https://doi.org/10.5209/rev_POSO.2015.v52.n2.45203

ALCOTT, B. The sufficiency strategy: Would rich-world frugality lower environmental impact? Ecological Economics, v. 64, n. 4, p. $770-786,2008$. https://doi.org/10.1016/j.ecolecon.2007.04.015

BALLET, J., BAZIN, D., DUBOIS, J.L., MAHIEU, F.R. A note on sustainability economics and the capability approach. Ecological Economics, v. 70, n.11, p. 1831-1834, 2011. https://doi.org/10.1016/j.ecolecon.2011.05.009

BALLET, J., KOFFI, J.M., PELENC, J. Environment, justice and the capability approach. Ecological Economics, v. 85, p. 28-34, 2013. https://doi.org/10.1016/j.ecolecon.2012.10.010 BAUMGÄRTNER, S.; QUAAS, M. What is sustainability economics? Ecological Economics, v. 69, n. 3, p. 445-450, 2010. https://doi.org/10.1016/j.ecolecon.2009.11.019 BRASIL. Ministério do Meio Ambiente. Plano de ação para produção e consumo sustentáveis - PPCS. Sumário Executivo. Brasília, 2011.

BURKETT, P. Marxism and ecological economics: toward a red and green political economy. Chicago: Haymarket Books, 2009.

CAMPBELL, C. The romantic ethic and the spirit of modern consumerism. Oxford: Blackwell Publishers, 1987.

CLARK, A. E.; FRIJTERS, P.; SHIELDS, M.A. Relative income, happiness, and utility: an explanation for the Easterlin paradox and other puzzles. Journal of Economic Literature, v. 46, n. 1, p. 95-144, 2008. https://doi.org/10.1257/jel.46.1.95

COMISSÃO MUNDIAL SOBRE O MEIO AMBIENTE E DESENVOLVIMENTO (CMAD). Nosso Futuro Comum. Rio de Janeiro: Ed. da Fundação Getúlio Vargas, 1991.

EASTERLIN, R.A. Does economic growth improve the human lot? Some empirical evidence. In: DAVID, P.A.; REDER, M.W. (Orgs.) Nations and households in economic growth: essays in honor of Moses Abramovitz. New York: Academic Press, 1974. p. 89-125. https://doi.org/10.1016/B978-0-12-205050-3.50008-7

ELLIOTT, R. Making up people: consumption as a symbolic vocabulary for the construction of identity. In: EKSTRÖM, K.M.; BREMBECK, H. (Orgs.) Elusive consumption. Oxford: Berg, 2004. p. 129-143.

FELLNER, W.; SPASH, C.L. The illusion of consumer sovereignty in economic and neoliberal thought [SRE-Disc 2014/02]. Institute for the Environment and Regional Development, Vienna University of Economics and Business, Vienna, 2014.

FERREIRO, M. de F. Direito de propriedade e ética da terra: o contributo de Aldo Leopold. e-cadernos ces, v. 5, p. 8-20, 2009. https://doi.org/10.4000/eces.260

FISCHER, C.; GRIESSHAMMER, R. When less is more - sufficiency: terminology, rationale and potentials [Working Paper 2]. Institute for Applied Ecology, Freiburg, 2013.

FOSTER, J. B. Marx's ecology: materialism and nature. New York: Monthly Review Press, 2000.

FUCHS, D.; DI GIULIO, A.; GLAAB, K.; LOREK, S.; MANIATES, M.; PRINCEN, T.; ROPKE, I. Power: the missing element in sustainable consumption and absolute reductions research and action. Journal of Cleaner Production, v. 132, p. 298-307, 2015. https://doi.org/10.1016/j.jclepro.2015.02.006

HEINDL, P.; KANSCHIK, P. Ecological sufficiency, individual liberties, and distributive justice: implications for policy making. Ecological Economics, v. 126, p. 42-50, 2016. https://doi.org/10.1016/j.ecolecon.2016.03.019

KOVEL, J. The enemy of nature: the end of capitalism or the end of the world? 2 ed. London \& New York: Zed Books, 2002. 
LATOUCHE, S. Sustainable consumption in a "de-growth" perspective. In: ZACCAÏ, E. (Org.) Sustainable consumption, ecology and fair trade. New York: Routledge, 2007. p. 178-185.

LOREK, S.; FUCHS, D. Strong sustainable consumption governance - precondition for a degrowth path? Journal of Cleaner Production, v. 38, p. 36-43, 2013. https://doi.org/10.1016/j.jclepro.2011.08.008

LÖWY, M. From Marx to Ecosocialism. Capitalism Nature Socialism, v. 13, n. 1, p. 121133, 2001. https://doi.org/10.1080/104557502101245413

LÖWY, M. Ecosocialism: a radical alternative to capitalist catastrophe. Chicago: Haymarket Books, 2015.

MANSVELT, J. Geographies of consumption. London: Sage Publications, 2005.

MARTINEZ-ALIER, J. The environmentalism of the poor: a study of ecological conflicts and valuation. Cheltenham, UK: Edward Elgar, 2002. https://doi.org/10.4337/9781843765486

MILLER, D. (Org.) Acknowledging consumption: A review of new studies. London: Routledge, 1995.

NÆSS, A. Ecology, community and lifestyle. Cambridge: Cambridge University Press, 1989. https://doi.org/10.1017/CBO9780511525599

ROPKE, I. Consumption in ecological economics. In: NEUMAYER, E. (Org.) Online Encyclopaedia of Ecological Economics. Aalborg: International Society for Ecological Economics, 2005. p. 19.

SÁ BARRETO, E. Desmaterialização desmistificada: o potencial poupador da tecnologia e suas implicações ambientais. In: Encontro Nacional de Economia da ANPEC, 41., 2013, Foz do Iguaçu. Anais... Foz do Iguaçu: ANPEC, 2014.

SACHS, I. Estratégias de transição para o século XXI. In: BURSZTYN, M. (Org.) Para pensar o desenvolvimento sustentável. São Paulo: Brasiliense, 1993. p. 29-56.

SAWYER, D. Population and sustainable consumption in Brazil. In: HOGAN, D.J.; BERQUO, E.S.; COSTA, H.S.M. (Orgs.) Population and environment in Brazil: Rio+10. Campinas: CNPD/ABEP/NEPO, 2002. p. 225-254.

SEN, A. Development as freedom. Oxford: Oxford University Press, 1999.

SEN, A. Inequality reexamined. Oxford: Oxford University Press, 1992.

SCERRI, A. Ends in view: the capabilities approach in ecological/sustainability economics. Ecological Economics, v. 77, p. 7-10, 2012. https://doi.org/10.1016/j.ecolecon.2012.02.027

SEDACKLO, M.; MARTINUZZI, A.; ROPKE, I.; VIDEIRA, N.; ANTUNES, P. Participatory systems mapping for sustainable consumption: discussion of a method promoting systemic insights. Ecological Economics, v. 106, p. $33-43,2014$.

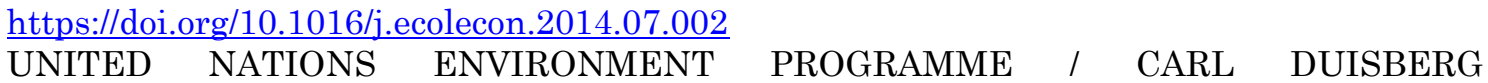
GESELLSCHAFT (UNEP/CDG). Sustainable production and consumption: creating opportunities in a changing world. Berlin: CDG, 2000.

VILLALBA-EGUILUZ, C. U., ETXANO, I. Buen vivir vs development (II): the limits of (neo-)extractivism. Ecological Economics, v. 138, p. 1-11, 2017. https://doi.org/10.1016/j.ecolecon.2017.03.010

WILK, R. Questionable assumptions about sustainable consumption. In: REISCH, L.A.; ROPKE, I. (Orgs.) The ecological economics of consumption. Cheltenham, UK: Edward Elgar, 2004. p. 17-31.

ZAFFARONI, E.R. La Pachamama y el humano. In: ACOSTA, A.; MARTÍNEZ, E. (Orgs.) La naturaleza con derechos: de la filosofía a la política. Quito: Abya-Yala, 2011. p. 25137. 